\title{
TECNOLOGIA ASSISTIVA - UMA REVISÃO DO TEMA
}

\section{Patrícia Rocha Rodrigues ${ }^{1}$ e Lynn Rosalina Gama Alves ${ }^{2}$}

E-mail: pacica2001@gmail.com ${ }^{1}$, lynnalves@gmail.com ${ }^{2}$

Artigo submetido em agosto/2013 e aceito em dezembro/2013

\section{RESUMO}

Este artigo tem como objetivo destacar a fatores que têm contribuído para sua necessidade de ampliação das discussões a emergência na atualidade, bem como a respeito da Tecnologia Assistiva, nos diversos evolução conceitual que tem sofrido e as espaços acadêmicos e sociais. Para isso, faz relações que se estabelecem com as uma revisão sobre o tema, destacando os tecnologias da Informação e Comunicação.

PALAVRAS-CHAVE: Tecnologia Assistiva, deficiência, acessibilidade.

\section{ASSISTIVE TECHNOLOGY - A REVIEW}

\section{ABSTRACT}

This paper objective is to emphasize the need for a broad discussion about Assistive emergency of this type of technology. Technology in academia and society in general. In order to achieve this objective, the paper reviews the literature about the theme. It Furthermore, the paper presents the evolution of the Assistive Technology concept and the relations that this concept has with information and communication technologies.

highlights the factors that contributed to the

KEYWORDS: Assistive Technology, disability, accessibility. 


\section{TECNOLOGIA ASSISTIVA - UMA REVISÃO DO TEMA}

\section{INTRODUÇÃO}

A Tecnologia Assistiva (TA) representa atualmente um área em ascensão, impulsionada, principalmente, pelo novo paradigma da inclusão social, que defende a participação de pessoas com deficiência nos diversos ambientes da sociedade. Para a maioria dessas pessoas, os recursos de TA são essenciais para a mobilidade, atividades relacionadas à aprendizagem, trabalho, comunicação e interação com o mundo.

Apesar da crescente demanda da área, em nosso país, as pesquisas e projetos de TA ainda são escassos. O tema, na maior parte das vezes, fica restrito aos especialistas envolvidos com pessoas com deficiência, como se esse assunto não coubesse na pauta de discussões e ações de outras áreas do conhecimento. Assim, este estudo busca fazer uma breve revisão sobre os principais pontos relacionados à TA, como forma de destacar a necessidade de ampliação das discussões em diversos espaços acadêmicos e sociais.

Serão abordados, inicialmente, os fatores que têm promovido maior interesse pelos recursos e serviços de TA no Brasil. Nesse sentido, além da influência do paradigma inclusivo na nossa sociedade, serão apontados dados estatísticos referentes ao público alvo dessa área, informações sobre a legislação, políticas públicas nacionais e as conclusões da Pesquisa Nacional de TA, realizada entre os anos 2005 a 2008.

Em seguida, destacaremos a trajetória histórica de sistematização, construção e formulação do conceito de TA, nas esferas internacional e nacional. Demonstraremos que tal processo ainda está em pleno desenvolvimento, e, portanto, aberto a reflexões que permitam a superação de distorções e contribuam para uma maior precisão conceitual.

Por fim, será analisada a relação que se estabelece entre TA e Tecnologias da Informação e Comunicação (TIC), assinalando estas últimas como elementos instituintes/instituídos da/na condição humana. Nessa lógica, poderemos sinalizar a importância da qualidade da participação de pessoas com deficiências e de idosos, nos processos tecnológicos da atualidade.

A análise desses pontos tem como referencial teórico as contribuições de alguns autores que se dedicam às categorias tecnologia, deficiência e TA. São destacados Lévy $(2010,2011)$ e Lima Júnior (2004), quanto ao conceito de tecnologia; Diniz (2007), para as considerações sobre a deficiência, e consequentemente o paradigma de inclusão, além de Galvão Filho (2009; 2013), como principal teórico que aborda a tecnologia assistiva em nosso país.

As conclusões incidem sobre a necessidade de diferentes áreas do conhecimento voltarem-se também para esse tema, visando à integração de saberes em prol de efetivas ações transformadoras das práticas excludentes de nossa sociedade em relação às pessoas com deficiência.

\section{TECNOLOGIA ASSISTIVA, CRESCIMENTO E DEMANDAS}

A área de TA vem crescendo nos últimos anos como consequência de alguns fatores que têm impulsionado demandas de recursos e serviços destinados às pessoas com deficiência. $O$ principal desses fatores refere-se ao destaque que se tem dado aos arranjos sociais como 
promotores ou não de acessibilidade para essas pessoas. Nessa concepção, são questionados todos os mecanismos que de alguma forma impedem a participação plena nos diferentes espaços e papéis sociais e, busca-se formas de garantir efetivamente tal participação como direito de todos.

Diniz (2007) ao defender um conceito de deficiência, segundo um modelo social e antropológico, destaca a experiência histórica de opressão e apartação social vivida pelas pessoas com algum tipo de deficiência. Para essa autora, esse fato é decorrente da incapacidade social em prever e incorporar a diversidade humana. Além disso, a concepção de deficiência fora marcada (e ainda é, em muitos contextos) pelo modelo médico que costuma considerar as limitações como consequências intrínsecas ao corpo deficiente.

Assim, nessa nova perspectiva de sociedade que se mobiliza para garantir a participação de todos, independentemente de quaisquer características, surge a necessidade de ampliação dos recursos de TA nos mais diferentes espaços.

No Brasil, as pessoas com deficiência (público alvo da TA) representam o percentual de 23,9\% da população nacional, segundo os dados do Censo 2010 realizado pelo Instituto Brasileiro de Geografia e Estatística (IBGE, 2012, p. 114). Esse número apresenta um significativo aumento, se comparado aos $14,5 \%$ registrados no Censo de $2000^{1}$. Além disso, é importante destacar que o público ao qual a TA se destina também engloba os idosos. Nesse sentido, Diniz $(2007$, p. 78) destaca que "ser velho é experimentar o corpo deficiente". E essa população também vem crescendo: em 2000 era representada pelo percentual de 5,9\%, passando para 7,4 em 2010 (IBGE, 2010). Esses números, por si só expressivos, tomam dimensões maiores, uma vez que aqueles que convivem de forma direta ou indireta com idosos e/ou pessoas com deficiência também são impactados com situações limitantes.

Atualmente, algumas políticas públicas brasileiras também têm contribuído para gerar demandas de TA em larga escala. Uma delas é a Política Nacional de Educação Especial na Perspectiva da Educação Inclusiva (BRASIL, 2008), com suas normas e orientações para a inclusão de crianças, jovens e adultos com deficiência nas escolas regulares. A plena participação desses alunos, em muitos casos, só pode ser garantida com a presença dos recursos de TA, não só no ambiente escolar, mas para permear todos os processos de aprendizagem desses sujeitos.

Outra contribuição importante é a Política de Inclusão Digital (BRASIL, 2009b), com ações que possibilitam a implantação e a manutenção de telecentros públicos e comunitários em todo o território nacional. Mesmo que tal política não faça referência direta à necessidade de recursos de TA nos telecentros, podemos presumir que isso é essencial diante da diversidade do público ao qual se destina, e também em decorrência das leis brasileiras que garantem a acessibilidade em diversos espaços.

O Decreto 5.296/04 (BRASIL, 2004) em seu artigo 47ํㅡ, por exemplo, torna obrigatório que os portais e sítios eletrônicos da administração pública garantam a acessibilidade para usuários deficientes visuais. O Comitê Brasileiro de Acessibilidade, vinculado à Associação Brasileira de Normas Técnicas, também dispõe de orientações para a acessibilidade em espaços virtuais, expressas na norma 15599:2008 que trata da comunicação na prestação de serviços (ABNT, 2008). Da mesma forma, temos o Modelo de Acessibilidade de Governo Eletrônico - e-MAG

\footnotetext{
1 Conferir em: <http://www.ibge.gov.br/home/presidencia/noticias/20122002censo.shtm>. Acesso em: 28 nov. 2013.
} 
(BRASIL, 2011a), que consiste em um conjunto de recomendações a ser considerado para que o processo de acessibilidade dos sítios e portais do governo brasileiro seja conduzido de forma padronizada e de fácil implementação para o usuário com deficiência. Além disso, o Decreto 6.949/09 (BRASIL, 2009b) promulgou a Convenção Internacional sobre os Direitos das Pessoas com Deficiência, elaborada pela Organização das Nações Unidas (ONU). Esta Declaração internacional, em seu artigo 9o, alínea g, define a obrigatoriedade de promoção do acesso a novos sistemas e tecnologias da informação e comunicação, inclusive à Internet (BRASIL, 2011c).

Uma terceira política de grande influência, e com ações diretas sobre a área de TA, é o Plano Nacional dos Direitos da Pessoa com Deficiência (Plano Viver sem Limites), instituído em 2011 pelo Governo Federal (BRASIL, 2011b). Em seu eixo temático "acessibilidade", esse plano inclui o Programa Nacional de TA, com ações voltada para a ampliação do número de produtos dessa área, através de investimento em pesquisas e projetos e, a criação de linha de crédito facilitado para aquisição de recursos de TA - o BB Crédito, para pessoa física (BRASIL, 2013).

Diante de todos esses fatores, inclusive na legislação, que têm impulsionado recentes pesquisas e desenvolvimento de recursos e serviços de TA, em nosso país, os resultados ainda são muito reduzidos. Garcia e Galvão Filho (2012) apontam tal realidade e as consequências dessa escassez:

Os estudos e análises referentes aos processos de pesquisa e desenvolvimento na área da Tecnologia Assistiva no Brasil ainda são bastante escassos. Raros mesmo. A escassez desses estudos acarreta, como uma de suas consequências mais importantes, grandes dificuldades para a definição e formatação de políticas públicas nessa área e para a configuração adequada de iniciativas de apoio e fomento a projetos com esse foco (GARCIA; GALVÃO FILHO, 2012, p. 8).

A Pesquisa Nacional de Tecnologia Assistiva (PNTA), viabilizada pela Secretaria de Ciência e Tecnologia para a Inclusão Social em parceria com o Instituto de Tecnologia Social (ITS BRASIL), realizou um levantamento entre os anos 2005-2006, 2007-2008 sobre a inovação na área de TA no Brasil, identificando e caracterizando as instituições que desenvolvem pesquisas e produzem ajudas técnicas ou produtos de apoio. Garcia e Galvão Filho (2012) analisam os dados obtidos nessa pesquisa, destacando algumas conclusões importantes para a reflexão sobre o contexto da TA no Brasil. Dentre elas, está o fato de que a maior parte dos projetos desenvolvidos se concentraram em apenas três Estados da União (77\% deles entre RS, SP e RJ). Os autores apontam, a partir desses dados, "a necessidade de que se estudem formas de aumentar a capilaridade e distribuição das ações e pesquisas por todos o território nacional" (GARCIA; GALVÃO FILHO, 2012, p. 58). Essa necessidade torna-se ainda mais importante nos estados do Nordeste, uma vez que, segundo o IBGE (2010), sua população com deficiência representa o segundo maior percentual dentre as regiões brasileiras. Outro problema identificado na PNTA é que os projetos concentram-se mais em pesquisas $(52,2 \%)$ do que em produtos ( $23 \%$ ) e serviços $(24,8)$, o que evidencia a necessidade de avanços na produção e distribuição de inovações (GARCIA; GALVÃO FILHO, 2012, p. 59). Além disso, a maior parte dos projetos estão relacionados às deficiências física e visual, deixando as demais carentes de iniciativas concretas para as suas especificidades, principalmente quando atentamos para as pessoas com deficiência múltipla.

Garcia e Galvão Filho (2012) chamam a atenção ainda para o fato de que a questão da acessibilidade para esses pessoas deve deixar de ser percebida como apenas opcional ou secundária, mas ser tratada como "um direito fundamental que possibilita o exercício pleno da 
cidadania e o acesso a outros direitos básicos como aprender, comunicar-se, trabalhar, divertirse, etc." (GARCIA; GALVÃO FILHO, 2012, p. 60). Nesse sentido, o acelerado avanço tecnológico da atualidade, principalmente na área das TIC, pode ter um papel importante na abertura de novos caminhos, soluções e perspectivas no âmbito da TA.

\section{UM CONCEITO EM DESENVOLVIMENTO}

O conceito de TA remete a concepções e paradigmas diferentes ao longo da história, com características específicas a partir do referencial de cada país. Contudo, em todas essas variáveis podemos identificar como objetivo essencial a qualidade de vida, com referência a processos que favorecem, compensam, potencializam ou auxiliam habilidades ou funções pessoais comprometidas por algum tipo de deficiência ou pelo envelhecimento.

O uso de recursos de TA sempre esteve presente na história da humanidade, até mesmo nos primórdios de sua existência, quando por exemplo, homens primitivos usavam pedaços de madeira como bengala improvisada. Com os avanços tecnológicos, esses recursos vão ganhando maior eficiência e abrangência, revelando processos criativos e transformativos no imbricamento homem-técnica.

Mas é somente em 1988 que o termo tecnologia assistiva é criado oficialmente, como elemento jurídico dentro da legislação norte-americana, para garantir o benefício de recursos e serviços favorecedores de uma vida mais independente, produtiva e incluída no contexto social (BERSCH, 2008). Assim, o termo surge com abrangência em duas dimensões: recursos, que são os equipamentos, produtos ou sistemas, e serviços, destinados a auxiliar diretamente às pessoas com deficiência a selecionar, adquirir ou usar os recursos de TA.

Galvão (2009) relata que na Europa, onde é comum uso dos termos ajudas técnicas ou tecnologia de apoio, duas organizações têm forte influência sobre o conceito e ações relacionados ao tema: o Consórcio EUSTAT (Empowering Users Through Assistive Technology) e o Consórcio EASTIN (Rede Europeia de Informação de Tecnologias de Apoio). O EUSTAT engloba organizações para promoção de ações e estudos com o foco em produtos e, principalmente, em serviços. O EASTIN, criado em 2004, tem como objetivo a criação de uma rede internacional de informações, servindo a todos os países europeus. Apesar desses segmentos fazerem referência a um conceito amplo e abrangente, diversos países, inclusive na Europa, acabam por adotar a classificação da Norma Internacional ISO 9999:2002, que é basicamente orientada para a categorização de produtos, e que reforça a concepção de Ajudas Técnicas como apenas ferramentas. Por esse motivo, o Consórcio EUSTAT recomenda a classificação HEART (Horizontal European Activities in Rhabilitation Technology) que propõe três grandes áreas de formação em relação às Tecnologias de Apoio: componentes técnicos, componentes humanos e componentes socioeconômicos. Essa classificação tem ganhado força na atualidade, principalmente em decorrência do paradigma inclusivo, o qual desloca as limitações de funcionalidade e possibilidades de participação do âmbito restrito à deficiência em si, para situá-las a partir das barreiras impostas pelo ambiente físico e social.

No Brasil, observa-se que as expressões Tecnologia Assistiva, Ajudas Técnicas e Tecnologia de Apoio são utilizadas, mais frequentemente, como sinônimos. A legislação brasileira utiliza a expressão Ajudas Técnicas, e, mesmo no Decreto 5296/2004, que tem como temática principal a acessibilidade, o conceito inclui apenas "produtos, instrumentos, equipamentos ou tecnologia" 
(BRASIL, 2004). Apesar dessa limitação, o art. 8o, inciso IX, desse decreto define um conceito importante também para a concepção de recurso e serviços acessíveis às pessoas com deficiência - o conceito de Desenho Universal:

(...) concepção de espaços, artefatos e produtos que visam atender simultaneamente todas as pessoas, com diferentes características antropométricas e sensoriais, de forma autônoma, segura e confortável, constituindo-se nos elementos ou solução que compõem a acessibilidade (BRASIL, 2004).

Com o intuito de superar algumas limitações e promover uma padronização da terminologia adotada no país, o Comitê de Ajudas Técnicas, ligado à Secretaria Especial dos Direitos Humanos da Presidência da República (SEDH/PR), aprovou a adoção da seguinte formulação para o conceito de TA:

(...) área do conhecimento, de característica interdisciplinar, que engloba produtos, recursos, metodologias, estratégias, práticas e serviços que objetivam promover a funcionalidade, relacionada à atividade e participação, de pessoas com deficiência, incapacidades ou mobilidade reduzida, visando sua autonomia, independência, qualidade de vida e inclusão social (BRASIL, 2007).

Essa ampla concepção, traz bases importantes, que representam avanços conceituais relacionados ao tema. Em primeiro lugar, a TA (expressão no singular) é definida como área de conhecimento, e portanto, envolve não só produtos, mas também, metodologias, estratégias e serviços. Além disso, ao atribuir a característica interdisciplinar, deixa de ser atribuição exclusiva do âmbito da saúde, e passa a ser permeada por diferentes áreas do conhecimento. Por fim, seu objetivo condiz com os direitos das pessoas com deficiência, idosos, e com a necessidade da inclusão social.

Galvão Filho (2013) ressalta que atualmente se tem gerado algumas distorções quanto a delimitação dos recursos que podem ser considerados TA, devido justamente à amplitude conceitual proposta e ao crescente interesse pelo tema em diferentes espaços. Dessa forma, há uma tendência equivocada em considerar como TA qualquer recurso relacionado a pessoas com deficiência, mesmo que este possa ser usado por pessoas sem deficiência, com as mesmas finalidades. Assim, na busca de uma maior precisão conceitual, esse autor considera que:

A Tecnologia Assistiva, como um tipo de mediação instrumental, está relacionada com os processos que favorecem, compensam, potencializam ou auxiliam, também na escola, as habilidades ou funções pessoais comprometidas pela deficiência, geralmente relacionadas às funções motoras, funções visuais, funções auditivas e/ou funções comunicativas (GALVÃO FILHO, 2013, p. 8-9).

Nesse sentido, podemos destacar que a TA está estritamente relacionada a recursos de acessibilidade, destinados especificamente a pessoas com deficiência, incapacidades ou mobilidade reduzida. A finalidade, portanto, deve ser tomada como critério de identificação e classificação dos recursos de TA.

O uso de recursos educativos, principalmente aqueles relacionados às TIC, tem frequentemente causado esse tipo de equívoco. Muitas vezes, softwares educativos passam a ser rotulados como TA simplesmente pelo fato de poderem ser usados por alunos com deficiência. 
Ora, nesses casos, estes recursos podem ser caracterizados apenas como acessíveis, e não como TA, uma vez que podem ser utilizados por alunos sem deficiência com os mesmos objetivos de aprendizagem.

A partir dessa discussão, podemos reconhecer que a trajetória para a sistematização, construção e formulação do conceito de TA é ainda um processo em pleno desenvolvimento. Isso traz a necessidade de aprofundamento de algumas questões e divulgação dos avanços já alcançados, de forma que essa área possa crescer e atingir efetivamente seus objetivos.

\section{TIC E TA - UMA RELAÇÃO IMPORTANTE}

O acelerado avanço das TIC no mundo contemporâneo pode ser notado facilmente em vários espaços e em diferentes práticas sociais. Os recentes dispositivos digitais e a Internet têm aberto novas possibilidades comunicativas, cognitivas, sociais e culturais. Portanto, é importante que haja, necessariamente, uma relação bem próxima entre as TIC e a TA, de modo a garantir a equiparação de oportunidades para as pessoas com deficiência ou idosas.

Algumas TIC podem ser utilizadas como TA. Isso pode ser exemplificado com o uso do computador como caderno eletrônico por pessoas que não conseguem escrever usando lápis e caderno comuns, ou a utilização de plataformas de bate-papo com vídeos para comunicação entre surdos, usuários de língua de sinais, ou ainda, o uso de telas sensíveis ao toque, que permitem maior acessibilidade para pessoas com alguns tipos de deficiência física. Tecnologias como essas, e muitas outras, devido a suas características, permitem significativas melhorias no funcionamento motor, sensorial e/ou de comunicação dos indivíduos, sendo que em muitos casos, tornam-se a única maneira de execução dessas funções.

Santarosa (1997) considera que a utilização das TIC como TA pode ser classificada em quatro áreas básicas: sistemas auxiliares ou próteses para a comunicação; controle do ambiente; acessibilidade na educação e, inserção no mundo do trabalho profissional.

Em alguns casos, porém, para que as pessoas com deficiência ou idosas, possam usar as TIC, são necessários recursos de TA, como acionadores, teclados adaptados, softwares especiais ou até mesmo adaptações simples e artesanais. A partir dessa realidade, Galvão Filho e Damasceno (2008) apresentam uma divisão dos recursos de TA em três categoriais: adaptações físicas ou órteses; adaptações de hardware e softwares especiais de acessibilidade.

Ainda com respeito a essa relação entre TIC e TA, é importante levantar algumas reflexões a respeito das concepções que se tem sobre tecnologia. Ao sinalizarmos anteriormente que a origem da TA remonta aos primórdios da humanidade, convergimos para a ideia de que a própria tecnologia, de modo geral, se constitui em uma das dimensões da transformação do mundo humano por ele mesmo. Nesse sentido, Lévy (2011, p. 22) conclui que "o mundo humano é, ao mesmo tempo, técnico", mas, não numa perspectiva de razão instrumental, e sim com destaque a um processo complexo de influências mútuas entre os homens e as técnicas.

Vale destacar que é na modernidade que tecnologia passa a ser considerada como instrumento dissociado do homem, entendidas como suporte para fins de produtividade, assimilação e reprodução de modos de fazer. Tal concepção, é rebatida por Lima Júnior (2004), afirmando que a tecnologia deve ser entendida como: 
(...) um processo criativo através do qual o ser humano utiliza-se de recursos materiais e imateriais, ou os cria a partir do que está disponível na natureza e no seu contexto vivencial, a fim de encontrar respostas para os problemas de seu contexto, superando-os (LIMA JÚNIOR, 2004, p. 402).

Assim, entender os dispositivos tecnológicos para além de sua base material, significa reconhecê-los como elementos instituintes da condição humana, mas, também como elementos instituídos por ela. Contudo, nesse processo, a qualidade de apropriação dos indivíduos não é igualitária e, em muitos casos, produz excluídos.

A participação de pessoas com deficiência, e também de idosos, nos processos tecnológicos, remete-nos não apenas à necessidade de interfaces acessíveis, embora essas sejam elementos fundamentais. É necessário ainda que os indivíduos se apropriem dos recursos tecnológicos de forma mais autônoma, isto é, em condições de participar ativa e criticamente nas mais diversas práticas sociais.

\section{CONSIDERAÇÕES FINAIS}

A quem importa o tema da TA? Assim como qualquer assunto relacionado a pessoas com deficiência, a resposta a tal pergunta dependerá da concepção de sociedade que temos. $O$ atual paradigma da inclusão social redimensiona a questão da incapacidade, comumente associada ao indivíduo com deficiência, e destaca a responsabilidade coletiva na promoção de acessibilidade.

Devido a algumas políticas públicas como, por exemplo, a que promove a inclusão nas escolas regulares, a presença de pessoas com deficiência nos diversos espaços sociais é cada vez mais comum. Contudo, isso não significa que a equiparação de oportunidades venha sendo garantida. O que tem sido comum, é que essas pessoas, cotidianamente, têm que se ajustar à falta de acessibilidade, o que compromete sua plena participação em diferentes atividades sociais.

Diversos setores, principalmente o acadêmico, têm um papel importante na pesquisa, desenvolvimento e disponibilização da TA. É necessário, portanto, que as mais diferentes áreas do conhecimento voltem-se também para esse tema, e busquem uma integração de saberes em prol de efetivas ações transformadoras das práticas excludentes de nossa sociedade. Os desafios são de diferentes ordens, como arquitetônicos, comunicacionais, metodológicos, instrumentais, programáticos e atitudinais. Portanto, as frentes de trabalho também devem ser múltiplas e abrangentes.

É importante acrescentar, nesse sentido, que apenas a elaboração de projetos específicos para determinados grupos de pessoas (para surdos, para cegos, etc.) é insuficiente para atender a infinidade de demandas em constante transformação. É necessário que se avance para propostas que sejam concebidas tendo a acessibilidade como elemento intrínseco. Assim, caminharemos para a ideal do Desenho Universal, citado anteriormente.

Esse conceito foi debatido no 3을 Congresso Internacional sobre Desenho Universal, apoiado pela ONU, na cidade do Rio de Janeiro, em 2004, e resultou no que ficou conhecido como "Carta do Rio".

Concebemos o Desenho Universal como gerador de ambientes, serviços, programas e tecnologias acessíveis, utilizáveis equitativamente, de forma segura 
e autônoma por todas as pessoas - na maior extensão possível - sem que tenham que ser adaptados ou readaptados especificamente (CARTA DO RIO, 2004).

Enfim, acessibilidade, TA e Desenho Universal são conceitos interligados, e mutuamente influentes, que emergem a partir do desenvolvimento inclusivo da sociedade. Estamos vivendo uma época de maior conscientização sobre a importância da temática, contudo, ainda precisamos garantir que esses conceitos se concretizem efetivamente em todos os âmbitos sociais. Assim, cabe a todos nós, sociedade civil, setor privado, organizações nãogovernamentais, universidades, profissionais e governos, alguns papéis importantes, de acordo com a escala e a orientação das respectivas possibilidades.

\section{REFERÊNCIAS BIBLIOGRÁFICAS}

1. ABNT. NBR 15599:2008. Acessibilidade: comunicação na prestação de serviços. Comitê de Acessibilidade ABNT/CB-040. Rio de Janeiro: Associação Brasileira de Normas Técnicas. 2008. $39 \mathrm{p.}$

2. BERSCH, Rita. 2008. Introdução às Tecnologias Assistivas. Disponível em: < http://www.assistiva.com.br/Introducao_Tecnologia_Assistiva.pdf> Acesso em 22 ago. 2013.

3. BRASIL. Decreto $\mathrm{n} 05.296$, de 2 de dezembro de 2004. Regulamenta as Leis $\mathrm{n} 010.048$, de 8 de novembro de 2000, que dá prioridade de atendimento às pessoas que especifica, e 10.098, de 19 de dezembro de 2000, que estabelece normas gerais e critérios básicos para a promoção da acessibilidade das pessoas portadoras de deficiência ou com mobilidade reduzida, e dá outras providências. Diário Oficial [da] República Federativa do Brasil, Brasília, DF, 3 dez. 2004. Disponível em: < http://www.planalto.gov.br/ccivil_03/_ato20042006/2004/decreto/d5296.htm>. Acesso em 22 ago. 2013.

4. BRASIL. Ata VII - Comitê de Ajudas Técnicas - CAT. Secretaria Especial dos Direitos Humanos da Presidência da República (CORDE/SEDH/PR). 2007. Disponível para download em:< http://www.comunicacaoalternativa.com.br/artigos-cientificos>. Acesso em: 22 ago. 2013.

5. BRASIL. Ministério da Educação. Secretaria de Educação Especial. Política Nacional de Educação Especial na Perspectiva da Educação Inclusiva. Brasília: MEC/SEESP, 2008. Disponível em: < http://portal.mec.gov.br/arquivos/pdf/politicaeducespecial.pdf>. Acesso em: 22 ago. 2013.

6. BRASIL. Decreto 6949, de 25 de agosto de 2009. Promulga a Convenção Internacional sobre os Direitos das Pessoas com Deficiência e seu Protocolo Facultativo, assinados em Nova York, em 30 de março de 2007. Diário Oficial [da] República Federativa do Brasil, Brasília, DF, 26 ago. 2009a. Disponível em: < http://www.planalto.gov.br/ccivil_03/_ato2007-2010/2009 /decreto/d6949.htm>. Acesso em: 22 ago. 2013.

7. BRASIL. Decreto no 6.991, de 27 de outubro de 2009. Institui o Programa Nacional de Apoio à Inclusão Digital nas Comunidades - Telecentros.BR, no âmbito da política de inclusão digital do Governo Federal, e dá outras providências. Diário Oficial [da] República Federativa do Brasil, Brasília, DF, 28 out. 2009b. Disponível em: < http://dev.inclusaodigital.gov.br/wpcontent/uploads/2012/07/decreto_6991_27-10-20092.pdf>. Acesso em: 22 ago. 2013. 
8. BRASIL. Ministério do Planejamento, Orçamento e Gestão, Secretaria de Logística e Tecnologia da Informação; Ministério da Educação, Secretaria de Educação Profissional e Tecnológica. e-Mag Modelo de Acessibilidade em Governo Eletrônico. Brasília: MP, SLTI, 2011a. 69 p.

9. BRASIL. Decreto no 7.612, de 17 de novembro de 2011. Institui o Plano Nacional dos Direitos da Pessoa com Deficiência - Plano Viver sem Limite. Diário Oficial [da] República Federativa do Brasil, Brasília, DF, 18 nov. 2011b. Acesso em: < http://www.planalto.gov.br/ccivil_03/_Ato2011-2014/2011/Decreto/D7612.htm>. Acesso em: 22 ago. 2013.

10. BRASIL. Convenção sobre os Direitos das Pessoas com Deficiência. 4 ed., ver. e atual. Brasília: Secretaria Nacional de Promoção dos Direitos da Pessoa com Deficiência, 2011c. 100 p.

11. BRASIL. Viver sem Limites - Plano Nacional dos Direitos da Pessoa com Deficiência. Brasília: Secretaria de Direitos Humanos da Presidência da República / Secretaria Nacional de Promoção dos Direitos da Pessoa com Deficiência, 2013. 92 p.

12. CARTA DO RIO. Desenho Universal para um Desenvolvimento Inclusivo e Sustentável. Conferência Internacional sobre Desenho Universal - Desenhando para o século XXI. Rio de Janeiro, 12 dez de 2004. Disponível em: < http://www.rollingrains.com/2005/01/carta-do-riodesenho-universal-para-um-desenvolvimento-inclusivo-e-sustentavel---portuguese-

version.html>. Acesso em: 22 ago. 2013.

13. DINIZ, Débora. O que é deficiência. São Paulo: Brasiliense. 2007. 80 p.

14. GALVÃO FILHO, Teófilo A.; DAMASCENO, Luciana L. Programa InfoEsp: Prêmio Reina Sofia 2007 de Rehabilitación y de Integración. In: Boletín del Real Patronato Sobre Discapacidad. Ministerio de Educación, Política Social y Deporte, Madri, Espanha. n. 63, abril/2008. p. 14-23.

15. GALVÃO FILHO, Teófilo A. A Tecnologia Assistiva: de que se trata? In: MACHADO, G. J. C.; SOBRAL, M. N. (Orgs.). Conexões: educação, comunicação, inclusão e interculturalidade. Porto Alegre: Redes Editora, 2009. p. 207-235.

16. GALVÃO FILHO, Teófilo A. A construção do Conceito de Tecnologia Assistiva: Alguns novos interrogantes e desafios. 2013. Disponível em: < http://www.galvaofilho.net/TA_desafios .htm >. Acesso em: 22 ago. 2013.

17. GARCIA, Jesus Carlos D. GALVÃO FILHO, Teófilo A. Pesquisa Nacional de Tecnologia Assistiva. São Paulo: ITS BRASIL/MCTI-SECIS, 2012. 68 p.

18. IBGE. Censo demográfico 2010: características gerais da população, religião e pessoas com deficiência. Ministério do Planejamento, Orçamento e Gestão. Rio de Janeiro: Instituto Brasileiro de Geografia e Estatística, 2012. 215 p. Disponível em: <http://biblioteca.ibge.gov .br/visualizacao/periodicos/94/cd_2010_religiao_deficiencia.pdf>. Acesso em: 28 nov. 2013.

19. LÉVY, Pierre. As tecnologias da inteligência. O futuro do pensamento na era da informática. 2. ed. São Paulo: Editora 34, 2010. 208 p.

20. Cibercultura. 3. ed. São Paulo: Editora 34, 2011. 272 p.

21. LIMA JR, Arnaud S. de. Tecnologias intelectuais e educação: explicitando o princípio proposicional/hipertextual como metáfora para educação e o currículo. Revista da FAEEBA Educação e Contemporaneidade, Salvador, v. 13, n. 22, p. 401-416, jul/dez. 2004. 
22. SANTAROSA, Lucila Maria C. Escola virtual para a educação especial: ambiente de aprendizagem telemáticos cooperativos como alternativas de desenvolvimento. Revista de Informática Educativa, Bogotá, v. 10, n. 1, p. 115-138, 1997. 